\title{
Havayolu Taşımacılığı ile Ekonomik Büyüme Arasındaki Nedensellik Analizi: Türkiye Üzerine Ampirik Bir Uygulama
}

\section{Kasım KİRACI ${ }^{1}$}

\begin{abstract}
$\ddot{O} z$
Havayolu taşımacılı̆̆l, diğer ulaşım araçlarından farklı olarak tüketicilere yer ve zaman faydası să̆lamaktadır. Bu özellikleri sayesinde, havayolu taşımacılı̆̆ına olan talebin sürekli bir artış trendi içerisinde olduğu görülmektedir. Akademik araştırmalar havayolu talebini etkileyen en önemli faktörün gelir olduğunu ortaya koymaktadır. Dolayısıla, gelirin havayolu taşımacılı̆̆ının önemli bir belirleyicisi olduğu varsaylmaktadır. Bu çalışmada Türkiye'de havayoluna olan talep ile GSYH arasındaki ilişki 1960-2015 dönemi için ampirik incelenmiştir. Çalışmada yöntem olarak Toda ve Yamamoto (1995) nedensellik ve Hatemi-J (2012) asimetrik nedensellik analizleri kullanılmıştır. Çalışmanın bulguları, havayoluna olan talep ile ekonomik büyüme arasında anlamlı nedensellik ilişkisinin olduğunu göstermektedir.
\end{abstract}

Anahtar Kelimeler: Havayolu, GSYH, Nedensellik, Toda \& Yamamoto, Hatemi-J.

Jel Sinıflandırma Kodlart: E60, L91, L93.

\section{Causality Analysis Between Airline Industry and Economic Growth:}

\section{An Empirical Application on Turkey}

\begin{abstract}
Unlike other means of transport, airline industry provides space and time benefits for consumers. Due to this feature, it is seen that the demand for airline industry is in a continuous increase trend. Academic research shows that the most important factor influencing airline demand is income. Therefore, income is assumed to be an important determinant of airline industry. In this study, the relationship between the demand for the airline in Turkey and the GDP was examined empirically for the period 1960-2015. As a method of study, we used Toda and Yamamoto (1995) causality and Hatemi-J (2012) asymmetric causality tests. Findings of the study show that there is a significant causality relationship between demand for airline and economic growth.
\end{abstract}

Keywords: Airline Industry, GDP, Causality, Toda \& Yamamoto, Hatemi-J.

Jel Classification Codes: E60, L91, L93.

1 Dr. Öğr. Üyesi, İskenderun Teknik Üniversitesi, Havacılık Yönetimi Bölümü, kasim.kiraci@iste.edu.tr 


\section{GíRiș}

\section{K.KİRACI}

Havayolu taşımacıllı̆ı, sahip olduğu birkaç özellik sayesinde diğer ulaşım modlarından ayrılmaktadır. Bunlardan en önemlisi, uzak mesafeleri hızlı bir şekilde kat etme olanağı sağlamasıdır. Bu özellik, havayolu taşımacılığını önemli hale getirmekte ve toplumların ekonomik gelişimine ve farklı ulusların birbirleriyle etkileşimine önemli katkılar sağlamaktadır. Havayolu taşımacıllı̆ı aynı zamanda, sahip olduğu teknik olanaklar sayesinde yer ve zaman faydası sağlaması bakımından toplumlara sosyal, kültürel ve ekonomik açıdan birçok olanak sunmaktadır. Dolayısıyla, havayolu taşımacıllı̆ı ile ekonomik büyüme arasında bir nedensellik ilişkisinin olması beklenmektedir. Buna karşın söz konusu ilişkinin yönü konusunda belirsizlik söz konusudur. Diğer bir ifadeyle, bireylerin gelirinde meydana gelen artışla birlikte havayolu taşımacılığına olan talep artmaktadır (Baker vd., 2015; Hakim ve Merkert, 2016) ancak, havayolu taşımacılı̆̆ ve havacılık yatırımlarının da ekonomik büyümeye önemli katk1 sağladığ1 varsayılmaktadır (Banister ve Berechman, 2001; Henshervd., 2012). Dolayısıyla, havayolu taşımacılığı ile ekonomik büyüme arasında nasıl bir ilişki olduğu ve bu ilişkinin yönünün ne olduğunun ortaya çıkarılması incelemeye değer konulardır. Buna ek olarak, Türkiye'de havayolu taşımacıllğı ile ekonomik faaliyetler arasındaki iliş̧inin ampirik incelendiği akademik çalışmaların oldukça sınırlı düzeyde kaldığı görülmektedir (Ozan vd., 2014; Sivrikaya ve Tunç, 2013). Dolayısıyla, bu çalışmanın Türkiye'de havayolu taşımacıllğı ile ekonomik büyüme arasındaki ilişkinin yönünü ortaya çıkarması ve literatüre bu açıdan katkı sağlaması beklenmektedir.

Türkiye'de havayolu taşımacıllğının gelişimi temel olarak üç dönem halinde değerlendirilmektedir. İlk dönem, 1983 yılına kadar, neredeyse tüm sivil havacılık faaliyetlerinin devlet tarafindan kontrol edildiği, özel sektörün faaliyette bulunmasına olanak sağlanmadığı dönemdir. Bu dönem, 
1983 yılında çıkarılan 2920 Sayılı Sivil Havacılık Kanunu ile özel sektör havayolu firmalarının da havacılık faaliyetlerinde bulunmasına izin verilmesiyle sona ermiştir. 1983 yılından önce sivil havacılık faaliyetlerinin neredeyse tamamı bir kamu iktisadi teşebbüsü olan Türk Hava Yolları (THY) tarafından yürütülmekteydi. Dolayısıyla, 1983 yılında çıkarılan Sivil Havacılık Kanunu, Türkiye’de havayolu taşımacılığının serbestleşmesi önemli katkılar sağlamıştır. İkinci dönem, 1983 yılından başlayarak 2000’li yılların başına kadar devam eden ve Türkiye'de havayolu taşımacılığının dalgalı bir seyir izlediği dönemdir. Bu dönemde, havayolu taşımacılığının 1990’lı yılların başında meydana gelen Körfez Savaşı'ndan ve 1996 yılında Türkiye'de havayolu firmalarının finansal zorluklarla yüzleşmesi sonucu pazara girişe bir takım kısıtlamaların getirilmesinden önemli ölçüde etkilendiği görülmektedir. Üçüncü dönem ise, 2001 ve 2003 yıllarında yapılan bir takım yasal değişiklikler sonucu Türkiye'de havayolu pazarının liberal hale geldiği ve havayollarına bir takım vergi indirimi ve sübvansiyonların sağlandığı dönemdir.

2002 yıllından sonra Türkiye’de uçak sayısı, koltuk kapasitesi ve kargo miktarında önemli artışlar meydana gelmiştir. Örneğin; 2003 yılı itibariyle 162 olan uçak sayısı \%233 artışla 2016 yılında 540'a yükselmiştir. Koltuk kapasitesi aynı dönemde \%264 atış kaydetmiştir. Buna ek olarak, 2003 yılından 2016 yılına kargo kapasitesinin \%502 arttığı görülmektedir (SHGM, 2016:31-32). 


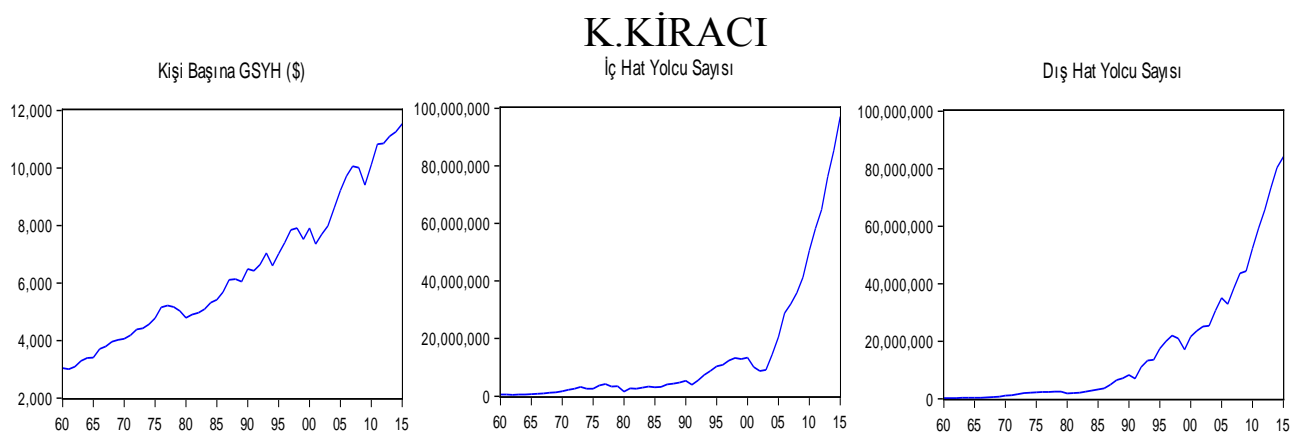

Şekil 1. Kişi Başına GSYH, İç Hat ve Dış Hat Yolcu Verileri

Kaynak: http://databank.worldbank.org/data/home.aspx

Şekil 1’de Türkiye'de 1960-2015 dönemine ilişkin kişi başına GSYH, iç hat yolcu sayısı ve dış hat yolcu sayısı verilerine yer verilmektedir. Kişi başına GSYH grafiğinde 1980, 2001 ve 2009 yıllarında aşağı yönlü kırılmaların meydana geldiği görülmektedir. İç hat yolcu sayısı ve dış hat yolcu sayısı grafikleri ise birbiriyle paralellik göstermektedir. Buna ek olarak, söz konusu grafiklerde 1980, 1990 ve 2001 y1llarında bir takım düşüşler meydana gelmesine karşın 2003 yılından itibaren yüksek bir artış hızına ulaşıldığı görülmektedir.

Türkiye'de havayolu taşımacılığı ile ekonomik büyüme arasındaki ilişkinin incelendiği bu çalışmanın devamı aşağıdaki gibi planlanmıştır. İkinci bölümde literatürde yapılmış çalışmalara, üçüncü bölümde çalışmada kullanılan yöntem ve verilere, dördüncü bölümde ulaşılan ampirik bulgulara ve son bölümde çalışmanın sonuçlarına yer verilecektir.

\section{LITERATÜR}

Havayolu talebini belirleyen birçok faktör söz konusudur ancak, gelirin talep üzerinde önemli etkisinin olduğu varsayılmaktadır. Dolayısıyla, son dönemde havayolu talebi ile ekonomik büyüme arasındaki nedensellik ilişkisinin ele alındığı birçok çalışma yapılmıştır. Buna ek olarak, bu ilişkinin şiddeti konusunda birçok ekonometrik modelin geliştirildiği görülmektedir. Örneğin; Ba-Fail vd., (2000) Suudi Arabistan için havayolu 
yolcu talebinin belirleyicileri konusunda, Baikgaki ve Daw (2013) Güney Afrika'da yerel havayolu yolcu talebini belirleyen faktörler konusunda ve Kopsch (2012) İsveç’te bölgesel havayolu taşımacılığını belirleyen değişkenler konusunda model geliştirmişlerdir. Abed vd., (2001) Suudi Arabistan'da uluslararası havayolu talebini ölçmek ve öngörüde bulunmak amacıyla ekonometrik modeller geliştirmiştir. Çalışmada uluslararası havayolu talebini ölçebilecek en uygun modelin, toplam harcama tutarı ve nüfus değişkenlerinin dâhil edildiği model olduğu vurgulanmıştır. Bunun yanı sıra, Valdes (2015) orta gelirli ülkelerde havayolu yolcu talebinin belirleyicilerinin neler olduğunu ampirik olarak incelemiştir. Chi (2014) GSYH, döviz kuru ve 11 Eylül terör saldırısının ABD’ye yapılan ve ABD'den yapılan uçuşlarda, havayoluna olan etkisini ele almıştır. Profillidis ve Botzoris (2015) dünyanın değişik coğrafi bölgelerinde havayolu yolcu taşımacılığı ile ekonomik büyüme arasındaki ilişkiyi ampirik olarak incelemiştir. Tam ve Hansman (2002) havayolu taşımacılığının ekonomik verimlilik ve bölgesel bağlantısallık üzerindeki etkisini, Mohmand vd., (2016) ulaşım altyapısının ekonomik büyüme üzerindeki etkisini, Van De Vijver vd., (2014) ise, Asya Pasifik bölgesinde ticaret ile hava yolcu talebi arasındaki ilişkiyi ampirik olarak ele almışlardır.

Sözü edilen bu çalışmaların yanı sıra, ekonomik büyüme ile havayolu taşımacılığı arasındaki kısa ve uzun dönemli nedensellik ilişkisinin ele alındığı çalışmaların da yapıldığı görülmektedir. Örneğin; Hakim ve Merkert (2016) Güney Asya’da ekonomik büyüme ile havayolu taşımacılığg arasındaki kısa ve uzun dönemli ilişkiyi ampirik olarak incelemiştir. Çalışmanın sonuçları, GSYH'den hem havayolu yolcu hem de hava kargo trafiğine doğru tek yönlü Granger nedensellik ilişskisinin varlığına işaret etmektedir. Chi ve Beak (2013) havayolu taşımacılığı ile ekonomik büyüme arasındaki kısa ve uzun dönemli dinamik nedensellik ilişkisini ampirik 


\section{K.KİRACI}

olarak ele almıştır. Çalışmanın bulguları, uzun dönemde havayolu yolcu sayısı ve hava kargo miktarının ekonomik büyüme üzerinde etkili olduğunu ortaya koymuştur. Marazzo vd., (2010) Brezilya’da havayolu taşımacılığ talebi ile ekonomik büyüme arasındaki ilişkiyi zaman serisi analiziyle incelemiştir. Çalışmanın bulguları, GSYH ile yolcu sayısı arasında güçlü bir ilişki olduğunu ve yolcu sayısındaki pozitif yönlü bir şokun GSYH üzerinde pozitif yönlü bir etki yarattı̆̆ını göstermektedir. Fernandesa ve Pacheco (2010), Brezilya'da GSYH ile havayolu yolcu trafiği arasındaki ilişkiyi Granger nedensellik analizi yöntemini kullanarak incelemiştir. Çalışmanın sonuçları, ekonomik büyümeden havayolu yolcu trafiğine doğru tek yönlü Granger nedenselliğin olduğunu göstermektir. Baker vd., (2015) Avustralya'da bölgesel havacılı ile ekonomik büyüme arasındaki koentegrasyon ve nedensellik ilişkisini incelemiştir. Çalışmada havalimanlarının bölgesel ekonomik kalkınma üzerinde ve ekonomik büyümenin bölgesel havayolu taşımacılığ üzerinde etkili olduğu sonucuna ulaşılmıştır.

Hu vd., (2015) Çin’de ekonomik büyüme ile bölgesel havayolu yolcu talebi arasındaki ilişkiyi panel veri analizi kullanarak analiz etmiştir. Çalışmanın bulguları, havayolu yolcu trafiğindeki \%1'lik artışın, ekonomik büyüme üzerinde \%0,943'lük artış yarattığını göstermiştir. Itani vd., (2013) Lübnanlı göçmenlerin havayolu yolcu talebi üzerindeki etkisini incelemiştir. Çalışmada, GSYH’nin havayolu trafiği üzerinde tutarlı ve istatistiki olarak anlamlı herhangi bir ilişkisinin olmadığı sonucuna ulaşılmıştır. Beyzatlar vd., (2014) 15 Avrupa ülkesinde taşımacılık ile GSYH arasındaki ilişkiyi panel veri analizi yöntemiyle incelemiştir. Çalışmanın ampirik sonuçlarına göre, 1970 ve/veya 2008 y1lında en düşük gelir düzeyine sahip ülkelerde, tek yönlü bir Granger nedensellik ilişkisine rastlanmış ya da hiçbir ilişkiye rastlanmamıştır. Buna ek olarak çalışmada, gelir ile ulaşım arasında endojen 
bir ilişki olduğu sonucuna ulaşılmıştır. Donzelli (2010) Güney İtalya'da düşük maliyetli havayolu taşımacılığının yerel ekonomi üzerindeki etkisini incelemiştir. Çalışmada düşük maliyetli havayolu faaliyetlerinin yerel ekonomi üzerinde yılda 14.6 milyon $€$ katkı sağladığı sonucuna ulaşılmıştır. Button ve Yuan (2013) ABD’de hava kargo taşımacılığı ile yerel ekonomik büyüme arasındaki ilişkiyi ampirik olarak ele almışlardır. Çalışmada hava kargo taşımacılığının yerel ekonomik büyüme üzerinde pozitif yönlü bir etkisinin olduğu sonucuna ulaşılmıştır. Literatürde ekonomik büyüme ile havayolu taşımacılığı arasında birçok çalışma yapılmasına karşın, Türkiye'de bu ilişkinin incelendiği hiçbir çalışma yapılmamıştır. Dolayısıyla, çalışmanın literatürdeki bu boşluğu doldurması ve literatüre önemli katkı sağlaması beklenmektedir.

\section{YÖNTEM}

$\mathrm{Bu}$ çalışmada havayolu talebi ile ekonomik büyüme arasındaki ilişkinin incelenmesi amaciyla ilk olarak Toda ve Yamamoto (1995) nedensellik testi kullanılmıştır. Toda ve Yamamoto (1995) testi, literatürde yer alan nedensellik analizlerinden farklı olarak eşbütünleşme şartına bağlı kalmaksızın (Erbaykal ve Okuyan, 2007:69) nedenselliğin ayrıştırılabileceği ve serilerin durağan olmaması durumunda bile seviye değerlerinin yer aldığ bir VAR modeli yaratılarak nedensellik ilişkisi ve yönünün saptanabileceği (Contuk ve Güngör, 2016:23) dolayısıyla, bütünleşme derecelerinin yanlış belirlenmesinden kaynaklanabilecek sorunları minimize eden bir testtir.

Toda ve Yamamoto (1995) nedensellik analizi değişkenlerin seviye değerlerinin yer aldığ1 Vektör Otoregressif (VAR) modeli üzerinden gerçekleştirilir. VAR modelinin optimal gecikme uzunluğu (p) ve değişkenlerin en büyük durağanlık seviyesi olan maksimum bütünleşme derecesi $\left(d_{\max }\right)$ belirlenerek VAR $\left(p+d_{\max }\right)$ VAR sistemi tahmin edilir. 


\section{K.KİRACI}

Daha sonra, VAR $\left(p+d_{\max }\right)$ sistemindeki $k$ gecikmelerinin katsayılarının grup olarak sıfıra eşit olup olmadığı MWALD testi aracılığıyla incelenir (Tandoğan ve Genç, 2016:66). Katsayılar grup olarak sıfıra eşittir şeklinde kurulan $H_{0}$ hipotezinin reddedilmesi, nedensellik ilişkisinin olduğunu göstermektedir. Havayolu taşımacılığı talebi ile GSYH arasındaki nedensellik ilişkisinin belirlenmesi amacıyla Toda ve Yamamoto (1995) nedensellik analizinde havayolu taşımacılığı talebinin göstergesi olarak iç hat yolcu sayısı (LIY) ve diş hat yolcu sayısı (LDY) değişkenlerinin logaritması ve kişi başına GSYH'nin logaritması (LGSYH) kullanılmıştır. LGSYH ile LIYY ve LDY değişkenlerinden oluşan ikili VAR sistemleri (1), (2), (3) ve (4) nolu denklemlerde sunulmuştur:

$$
\begin{aligned}
\mathrm{LGSYH}_{t}=\alpha_{0} & +\sum_{i=1}^{p+d} \alpha_{1(i+d)} L_{G S Y H_{t-(i+d)}}+\sum_{i=1}^{p+d} \alpha_{2(i+d)} L I Y_{t-(i+d)} \\
& +\varepsilon_{1 t} \\
\mathrm{LIY}_{t}=\beta_{0}+ & \sum_{i=1}^{p+d} \beta_{1(i+d)} L I Y_{t-(i+d)}+\sum_{i=1}^{p+d} \beta_{2(i+d)} L G S Y H_{t-(i+d)} \\
& +\varepsilon_{1 t} \\
\mathrm{LGSYH}_{t}=\delta_{0}+\sum_{i=1}^{p+d} \delta_{1(i+d)} L G S Y H_{t-(i+d)}+\sum_{i=1}^{p+d} \delta_{2(i+d)} L D Y_{t-(i+d)} & \varepsilon_{1 t}^{p+d} \\
& +\sum_{i=1}^{p+d} \omega_{1(i+d)} L D Y_{t-(i+d)}+\sum_{i=1} \omega_{2(i+d)} L G S Y H_{t-(i+d)} \\
& +\varepsilon_{1 t}
\end{aligned}
$$

$p$ VAR modelindeki gecikme sayısını, $p+d$ ise modele dahil edilen değişkenlerin maksimum bütünleşme derecesini ifade etmektedir. 
Dokuz Eylül Üniversitesi İktisadi ve İdari Bilimler Fakültesi Dergisi Cilt:33, Sayl:1, Yll:2018, ss. 197-216

Bu çalışmada, Toda ve Yamamoto (1995) nedensellik analizinin yanı sıra Hatemi-J (2012) asimetrik nedensellik analizi de kullanılmıştır. Hatemi-J (2012) asimetrik nedensellik analizi, seriler arasındaki pozitif ve negatif şoklar arasındaki ilişkiye odaklanmıştır. Pozitif ve negatif şoklar arasındaki ilişkinin, değişkenler arasındaki ilişkiden farklı olabileceği, ilk kez Granger ve Yoon (2002) tarafından ileri sürmüştür. Granger ve Yoon (2002) iktisadi/ekonomik serilerin şoklara birlikte tepki verdiklerinde eşbütünleşik olduklarını, ayrı ayrı tepki verdiklerinde ise aralarında bir eşbütünleşme ilişkisi olamayacağını ifade etmişlerdir. Daha sonraki aşamada, serilerin belirli bir türdeki şoka birlikte karşıllk verebileceklerini belirterek, veriyi birikimli pozitif ve negatif değişmelerine ayrıştırıp, bu parçalar arasındaki uzun dönemli ilişkiyi incelemişlerdir. Hatemi-J (2012) ise Granger ve Yoon (2002) yöntemini nedensellik analizi için geliştirmiştir. $\mathrm{Bu}$ asimetrik nedensellik testinde, Granger ve Yoon (2002) eşbütünleşme analizinde olduğu gibi serilerin dinamiğini anlamaya yardımcı olacak ve muhtemel geleceğe yönelik öngörü geliştirmeye firsat verecek saklı yapının ortaya çıkarılması hedeflenmektedir (Yılancı ve Bozoklu, 2014:214).

Hatemi-J (2012) testi, Toda ve Yamamoto (1995) nedensellik testi gibi nedensellik analizinde serilerin düzey/seviye değerlerini dikkate almaktadır. Fakat bu test, Toda ve Yamamato (1995) nedensellik testinden farklı olarak değişkenler arasındaki asimetrik nedensellik ilişkisinin ortaya çıkarılmasına izin vermektedir. Buna göre, orijinal seriye ait kümülatif negatif ve kümülatif pozitif şokları birbirinden ayrıştırarak herhangi bir değişkendeki negatif bir değişimin bir diğer ifadeyle, azalışın diğer bir değişkende de bir azalışa yol açıp açmadığı ve/veya herhangi bir değişkendeki bir artışın diğer bir değişkende de bir artışa yol açıp açmadığını sınayabilmektedir (Büberkökü ve Şahmaroğlu, 2016:8). 


\section{K.KİRACI}

$t=1,2, \ldots, T$ iken $y_{1,0}$ ve $y_{2,0}$ başlangıç değerlerini göstermek üzere aşağıdaki gibi bileşenlerine ayrılabilen $y_{1 t}$ ve $y_{2 t}$ gibi iki bütünleşik seri arasındaki nedensellik analizinin test edildiğini varsayılsın:

$$
\begin{aligned}
& \mathrm{y}_{1 t}=y_{1 t-1}+\varepsilon_{1 t}=\mathrm{y}_{1,0}+\sum_{i=1}^{t} \varepsilon_{1 i} \\
& \mathrm{y}_{2 t}=y_{2 t-1}+\varepsilon_{2 t}=\mathrm{y}_{2,0}+\sum_{i=1}^{t} \varepsilon_{2 i}
\end{aligned}
$$

Pozitif ve negatif şoklar aşağıdaki gibi gösterilir:

$$
\begin{array}{ll}
\varepsilon_{1 i}^{+}=\max \left(\varepsilon_{1 i}, 0\right), & \varepsilon_{1 i}^{-}=\min \left(\varepsilon_{1 i}, 0\right) \\
\varepsilon_{2 i}^{+}=\max \left(\varepsilon_{2 i}, 0\right), & \varepsilon_{2 i}^{-}=\min \left(\varepsilon_{2 i}, 0\right)
\end{array}
$$

Hacker ve Hatemi-J (2008), farklı tür şoklar arasında yapılan nedensellik testine Hatemi-J (2012) asimetrik nedensellik testi adını verilmektedir. Hatemi-J (2012) asimetrik nedensellik analizinde, dört önemli durum göze çarpmaktadır. Bunlar; VAR modelin gecikme uzunluğunun belirlenmesi, modele ilave edilecek ek gecikme uzunluğunun belirlenmesi, Wald test istatistiği için kritik değerlerin elde edilmesi ve zamana bağlı olarak nedensellik ilişkisinin değişmesi şeklinde sıralanmaktadır (Yılancı ve Bozoklu, 2014:214).

Lütkepohl (1985) ile Hacker ve Hatemi-J (2008) çalışmalarında VAR modelleri için Bayesyen ve Hannan- Quinn bilgi kriterlerinin, diğer bilgi kriterlerine göre daha iyi sonuçlar verdiğini ispat etmişlerdir. Hatemi-J (2003) ise bu iki bilgi kriterinin birbirinden farklı sonuçlar verebileceği durumlar olabileceğini öne sürerek, bu iki kriteri içeren yeni bir bilgi kriteri geliştirmiştir. Hatemi-J (2012) tarafindan tavsiye edilen bu yeni bilgi kriteri, HJC bilgi kriteridir. Bu çalışmada, Hatemi-J (2003) tarafından literatüre 
kazandırılan bu yeni bilgi kriteri (HJC) kullanılarak uygun gecikme uzunluğuna karar verilecektir.

\section{VERİ SETİ}

Bu çalışmada havayolu talebi ile ekonomik büyüme arasındaki ilişkinin ortaya çıkarılması amacıyla, 1960-2015 dönemi havayolu ve ekonomik büyüme verileri incelenmiştir. Havayolu talebini ölçmek amacıyla 19602015 dönemine ait iç hat yolcu sayısı ve dış hat yolcu sayısı verileri kullanılmıştır. Ekonomik büyümenin göstergesi olarak 1960-2015 dönemine ilişkin kişi başına GSYH (2010 sabit fiyatlarıyla \$) verisi kullanılmıştır. Çalışma kapsamında kullanılan tüm değişkenler, Dünya Bankası elektronik veri tabanından elde edilmiştir. Çalışmada iç hat yolcu sayısı için İY, dış hat yolcu sayısı için DY ve kişi başına gayrisafi yurtiçi hasıla için GSYH kısaltması kullanılmıştır. Çalışmada yer alan tüm değişkenler, doğal logaritmaları alınarak normalleştirilmiştir.

\section{AMPIRİK BULGULAR}

Toda ve Yamamoto (1995) nedensellik testinde sağlıklı sonuçlar elde edilmesi için, VAR modelindeki değişkenlerin maksimum bütünleşme derecesinin ve gecikme uzunluğunun doğru olarak belirlenmesi gerekmektedir. Bu çalışmada serilerin bütünleşme dereceleri Genişletilmiş Dickey-Fuller (ADF) ve Philips Perron (PP) birim kök testleri kullanılarak incelenmiştir. Uygun gecikme uzunluğunun belirlenmesinde LR, FPE, ACI, $\mathrm{SC}$ ve HQ bilgi kriterlerine göre karar verilmiştir. 
Tablo 1. Birim Kök Testi Sonuçları

\section{K.KİRACI}

\begin{tabular}{|c|c|c|c|c|c|}
\hline \multirow{3}{*}{$\begin{array}{c}\text { Variables } \\
\text { LGSYH }\end{array}$} & \multicolumn{2}{|c|}{ ADF- Test İstatistikleri (Seviye) } & \multicolumn{3}{|c|}{ ADF- Test İstatistikleri (1.fark) } \\
\hline & Sabit & Sabit ve Trend & Sabit & \multicolumn{2}{|c|}{ Sabit ve Trend } \\
\hline & $\begin{array}{ll}-0.543 & (0) \\
{[0.8740]} & \end{array}$ & $\begin{array}{l}-3.116 \\
{[0.1128]}\end{array}$ & $\begin{array}{l}-7.615 \\
{[0.0000]}\end{array}$ & $\begin{array}{l}-7.562 \\
{[0.0000]}\end{array}$ & (0) \\
\hline Lì & $\begin{array}{ll}0.202 & (0) \\
{[0.9704]} & \end{array}$ & $\begin{array}{l}-1.735 \\
{[0.7220]}\end{array}$ & $\begin{array}{l}-7.352 \\
{[0.0000]}\end{array}$ & $\begin{array}{l}-7.344 \\
{[0.0000]}\end{array}$ & (0) \\
\hline \multirow[t]{3}{*}{ LDY } & $\begin{array}{ll}-1.322 & (0) \\
{[0.6129]} & \end{array}$ & $\begin{array}{l}-1.854 \\
{[0.6645]}\end{array}$ & $\begin{array}{l}-6.522 \\
{[0.0000]}\end{array}$ & $\begin{array}{l}-6.571 \\
{[0.0000]}\end{array}$ & $(0)$ \\
\hline & \multicolumn{2}{|c|}{ PP- Test İstatistikleri (Seviye) } & \multicolumn{3}{|c|}{ PP- Test İstatistikleri (1.fark) } \\
\hline & Sabit & Sabit ve Trend & Sabit & \multicolumn{2}{|c|}{ Sabit ve Trend } \\
\hline LGSYH & $\begin{array}{l}-0.529 \\
{[0.8769]}\end{array}$ & $\begin{array}{l}-3.116 \\
{[0.1128]}\end{array}$ & $\begin{array}{l}-7.633 \\
{[0.0000]}\end{array}$ & $\begin{array}{l}-7.579 \\
{[0.0000]}\end{array}$ & (3) \\
\hline LìY & $\begin{array}{l}0.176 \\
{[0.9686]}\end{array}$ & $\begin{array}{l}-1.784 \\
{[0.6987]}\end{array}$ & $\begin{array}{l}-7.352 \\
{[0.0000]}\end{array}$ & $\begin{array}{l}-7.349 \\
{[0.0000]}\end{array}$ & $(1)$ \\
\hline LDY & $\begin{array}{l}-1.231 \\
{[0.6543]}\end{array}$ & $\begin{array}{l}-2.191 \\
{[0.4851]}\end{array}$ & $\begin{array}{l}-6.595 \\
{[0.0000]}\end{array}$ & $\begin{array}{l}-6.633 \\
{[0.0000]}\end{array}$ & (3) \\
\hline
\end{tabular}

Not 1: ADF birim kök testinde, parantez içerisindeki değerler SIC (Schwarz Info Criteria) kriterine göre seçilen gecikme uzunluklarını, köşeli parantez içindeki değerler ise ADF istatistiğinin olasılık değerlerini göstermektedir. Not 2: PP birim kök testinde, parantez içerisindeki değerler Newey West önerisi doğrultusunda Barlett Kernel için gecikme sayısını, köşeli parantez içindeki değerler ise PP istatistiğinin olasılık değerlerini göstermektedir.

$\mathrm{Bu}$ çalışmada değişkenlerin durağanlığının test edilmesi amacıyla ADF (Augmented Dickey Fuller) ve Phillips ve Perron (PP) birim kök testleri kullanılmıştır. Birim kök testi sonuçları düzey değerleri durağan olmayan verilerin birinci farkları alındığında durağan hale geldikleri görülmektedir. Diğer bir anlatımla, birinci Farkı alınan değişkenlerin ADF ve PP testi sonucunda durağan hale geldiği görülmektedir. 
Tablo 2. Toda-Yamamoto Nedensellik Testi Sonuçları

\begin{tabular}{|c|c|c|c|c|c|}
\hline \multicolumn{2}{|c|}{ Nedenselliğin Yönü } & $\chi^{2}$ Stat & VAR (p+d) & Prob. \\
\hline LGSYH & $\nRightarrow$ & LiY & 0.023 & $1+1$ & 0.8789 \\
\hline LìY & $\nRightarrow$ & LGSYH & 2.231 & $1+1$ & 0.1350 \\
\hline LGSYH & $\nRightarrow$ & LDY & 0.019 & $1+1$ & 0.8915 \\
\hline LDY & $\nRightarrow$ & LGSYH & 0.144 & $1+1$ & 0.7044 \\
\hline
\end{tabular}

Not: $\nRightarrow$ notasyonu nedenselliğin olmadığı, sıfır hipotezini göstermektedir. Tahmin edilen VAR modelinde LR, FPE, ACI, SC ve HQ kriterlerine göre en uygun olarak belirlenen 1 gecikme uzunluğu kullanılmıştır.

Tablo 2'de Toda Yamamoto (1995) nedensellik test sonuçlarına yer verilmiştir. Test sonuçları, değişkenler arasındaki ilişkilerde $H_{0}$ hipotezinin reddedilmediğini göstermektedir. Diğer bir ifadeyle, kişi başına GSYH'den, iç hat ve dış hat yolcu talebine doğru anlamlı bir nedensellik ilişkisinin olmadığını göstermektedir. Buna ek olarak iç hat ve dış hat yolcu talebinden kişi başına GSYH'ye doğru nedensellik ilişkisinin olmadığı görülmektedir. Simetrik nedensellik ilişkisinin olmadığı durumlarda asimetrik nedenselliğin incelenmesi, muhtemel ilişkinin ortaya çıkarılması açısından son derece önemlidir. Çalışmanın devamında Hatemi-J (2012) asimetrik nedensellik testi sonuçlarına yer verilecektir. 
K.KİRACI

Tablo 3. Hatemi-J (2012) Asimetrik Nedensellik Test Sonuçları

\begin{tabular}{|c|c|c|c|c|c|c|c|}
\hline \multicolumn{3}{|c|}{ Nedenselliğin Yönü } & \multirow{3}{*}{$\begin{array}{c}\text { MWALD } \\
\text { Stat } \\
88.734^{*}\end{array}$} & \multirow{3}{*}{$\begin{array}{c}\text { Gecikme } \\
1\end{array}$} & \multicolumn{3}{|c|}{ Bootstrap Kritik Değerleri } \\
\hline & & & & & $1 \%$ & $5 \%$ & $10 \%$ \\
\hline$L G S Y H^{++}$ & $\nRightarrow$ & $L I Y^{++}$ & & & 22.598 & 16.306 & 13.332 \\
\hline LGSYH ${ }^{--}$ & $\nRightarrow$ & $L I Y^{--}$ & $0.676 * * *$ & 1 & 26.866 & 6.174 & 0.457 \\
\hline$L I Y^{++}$ & $\nRightarrow$ & $L G S Y H^{++}$ & $140.851^{*}$ & 1 & 27.462 & 21.931 & 19.374 \\
\hline$L I Y^{--}$ & $\nRightarrow$ & $L G S Y H^{--}$ & $1.229 * * *$ & 1 & 26.107 & 5.986 & 0.477 \\
\hline LGSYH ${ }^{++}$ & $\nRightarrow$ & $L D Y^{++}$ & 42.909* & 1 & 27.439 & 21.612 & 18.870 \\
\hline LGSYH ${ }^{--}$ & $\nRightarrow$ & $L D Y^{--}$ & 0.091 & 1 & 26.033 & 5.782 & 0.538 \\
\hline$L D Y^{++}$ & $\nRightarrow$ & $L G S Y H^{++}$ & 111.066* & 1 & 27.451 & 22.076 & 19.243 \\
\hline$L D Y^{--}$ & $\nRightarrow$ & $L G S Y H^{--}$ & 0.103 & 1 & 7.187 & 3.803 & 2.621 \\
\hline
\end{tabular}

Not: $\nRightarrow$ notasyonu nedenselliğin olmadığı sıfır hipotezini göstermektedir. *** ve $* * *$ değerleri sirasıyla $\% 1, \% 5$ ve $\% 10$ anlam seviyesinde test istatistiğinin anlamlı olduğunu göstermektedir. Optimal gecikme uzunluğuna HJC bilgi kriterine göre karar verilmiştir. Bootstrap sayı1 10.000'dir.

Tablo 3'de zaman serilerde pozitif ve negatif şokları ayırabilme fonksiyonuna sahip Hatemi-J (2012) asimetrik nedensellik testi sonuçlarına yer verilmektedir. Test sonuçları incelendiğinde kişi başına GSYH’deki pozitif şoklardan iç hat ve dış hat yolcu talebindeki pozitif şoklara doğru \%1 anlam düzeyinde çift yönlü nedensellik ilişkisinin olduğu görülmektedir. Buna ek olarak, kişi başına GSYH'deki negatif şoklardan iç hat yolcu talebindeki negatif şoklara doğru \%10 anlam düzeyinde çift yönlü bir nedensellik ilişkisi söz konusudur. Son olarak, diş hat yolcu talebindeki pozitif şoklardan kişi başına GSYH'deki pozitif şoklara doğru \%1 anlam düzeyinde tek yönlü nedenselliğin olduğu görülmektedir. 


\section{SONUÇ}

Bu çalışmanın amacı Türkiye'de iç hat ve dış hat havayolu talebi ile kişi başına GSYH arasındaki simetrik ve asimetrik ilişkinin ampirik olarak incelenmesidir. Literatürde bu ilişkinin incelendiği çalışmaların nadiren yapılmış olması, bu çalışmanın literatüre sağlayacağı katkı bakımından oldukça önemlidir. Teorik açıdan ele alındığında, iç hat ve/veya dış hat havayolu talebi ile kişi başına GSYH arasındaki ilişki konusunda belirsizliğin olduğu görülmektedir. Bu çalışmada iç hat ve dış hat havayolu talebi ile kişi başına GSYH arasındaki ilişki ilk olarak Toda Yamamoto (1995) nedensellik analiziyle incelenmiştir. Çalışmanın bulguları söz konusu değişkenler arasında simetrik nedensellik ilişkisinin olmadığını göstermektedir. Çalışmada aynı zamanda seriler arasındaki ilişkinin daha detaylı ve derinlemesine incelenmesi amacıyla literatüre yeni kazandırılmış olan Hatemi-J (2012) asimetrik nedensellik testi uygulanmıştır.

Hatemi-J (2012) asimetrik nedensellik test sonuçları, kişi başına GSYH'den iç hat ve dış hat yolcu talebine doğru anlamlı nedensellik ilişkisinin varlığına işaret etmektedir. Buna göre, kişi başına GSYH’deki pozitif şoklardan iç hat yolcu talebindeki pozitif şoklara \%1 anlam düzeyinde ve kişi başına GSYH serisindeki negatif şoklardan iç hat yolcu talebindeki negatif şoklara \%10 anlam düzeyinde nedensellik ilişkisi söz konusudur. Buna ek olarak, kişi başına GSYH'deki pozitif şoklardan, dış hat yolcu talebindeki pozitif şoklara doğru \%1 anlam düzeyinde bir nedensellik ilişkisi tespit edilmiştir.

Çalışmada aynı zamanda iç hat ve dış hat havayolu talebinden kişi başına GSYH'ye asimetrik nedensellik ilişkisinin olup olmadığı incelenmiştir. Çalışmanın ampirik bulguları, iç hat ve dış hat havayolu talebindeki pozitif şoklardan, kişi başına GSYH'deki pozitif şoklara doğru \%1 anlam 


\section{K.KİRACI}

düzeyinde anlamlı bir nedensellik ilişkisinin olduğunu göstermektedir. Buna ek olarak çalışmanın sonuçları, dış hat havayolu talebindeki negatif şoklardan kişi başına GSYH'deki negatif şoklara doğru \%10 anlam düzeyinde anlamlı nedenselliğin varlığına işaret etmektedir. Çalışmada elde edilen bulgular genel olarak değerlendirildiğinde, kişi başına GSYH’deki şoklardan (pozitif ve negatif) iç hat yolcu talebindeki şoklara (pozitif ve negatif) doğru çift yönlü nedensellik ilişkisinin varlığı görülmektedir. $\mathrm{Bu}$ durum, Türkiye'de kişi başına GSYH ile iç hat havayolu talebi arasında çift yönlü bir nedensellik ilişkisinin varlığına işaret etmektedir. Dolayısıyla, kişi başına GSYH'de meydana gelen artışın, iç hat havayolu talebini arttırması beklenmektedir.

Çalışmanın sonuçları, kişi başına GSYH'deki pozitif şoklardan, dış hat havayolu talebindeki pozitif şoklara doğru çift yönlü nedensellik ilişkisinin olduğu göstermektedir. Bu durum, kişi başına GSYH'de meydana gelen yükselişin sadece iç hat havayolu talebini değil, dış hat havayolu talebini de etkilediğini göstermektedir. Dolayısıyla, Türkiye'de kişi başına GSYH'de meydana gelen artışın dış hat havayolu talebini pozitif yönlü etkilemesi beklenmektedir.

\section{KAYNAKÇA}

ABED, S. Y., BA-FAIL, A. O., JASIMUDDIN, S. M. (2001), An Econometric Analysis of International Air Travel Demand in Saudi Arabia. Journal of Air Transport Management, 7(3), 143-148.

BAIKGAKI, O. A., DAW, O. D. (2013), The Determinants of Domestic Air Passenger Demand in the Republic of South Africa. Mediterranean Journal of Social Sciences, 4(13), 389.

BA-FAIL, A. O., ABED, S. Y., JASIMUDDIN, S. M. (2000), The Determinants of Domestic Air Travel Demand in the Kingdom Of Saudi Arabia. Journal of Air Transportation World Wide, 5(2), 72-86. 

Cilt:33, Sayl:1, Yll:2018, ss. 197-216

BAKER, D., MERKERT, R., KAMRUZZAMAN, M. (2015), Regional Aviation and Economic Growth: Cointegration and Causality Analysis in Australia. Journal of Transport Geography, (43), 140-150.

BANISTER, D., BERECHMAN, Y. (2001), Transport Investment and the Promotion of Economic Growth. Journal of Transport Geography, 9(3), 209-218.

BEYZATLAR, M. A., KARACAL, M., YETKİNER, H. (2014), Granger-Causality between Transportation and GDP: A Panel Data Approach. Transportation Research Part A: Policy and Practice, (63), 4355.

BUTTON, K., YUAN, J. (2013), Airfreight Transport and Economic Development: An Examination of Causality. Urban Studies, 50(2), 329-340.

BÜBERKÖKÜ, Ö., ŞAHMAROĞLU, S. T. (2016), Beta Katsayılarındaki Değiş̧imin Açıklanmasında İşlem Hacminin Etkisinin İncelenmesi: Banka Hisselerine Dayalı Bir Analiz. İşletme Bilimi Dergisi, 4(1), 1-28.

CHI, J., BAEK, J. (2013), Dynamic Relationship between Air Transport Demand and Economic Growth in the United States: A New Look. Transport Policy, (29), 257-260.

CHI, J. (2014), A Cointegration Analysis of Bilateral Air Travel Flows: The Case of International Travel to and From the United States. Journal of Air Transport Management, 39, 41-47.

CONTUK, F. Y., GÜNGÖR, B. (2016), Finansal Piyasaların Gelişmesinin Ekonomik Büyüme Üzerine Etkileri: 1998-2014 Türkiye Örneği. Finans Politik \& Ekonomik Yorumlar, 53(611), 15.

DONZELLI, M. (2010), The Effect of Low-Cost Air Transportation on the Local Economy: Evidence from Southern Italy. Journal of Air Transport Management, 16(3), 121-126.

ERBAYKAL, E., OKUYAN, H. A. (2007), Türkiye'de Temel Makroekonomik Değişkenler ile Hisse Senedi Fiyatları Arasındaki Nedensellik İlişkisi. İktisat İşletme ve Finans, 22(260), 66-79. 


\section{K.KİRACI}

FERNANDES, E., PACHECO, R. R. (2010), The Causal Relationship between GDP and Domestic Air Passenger Traffic in Brazil. Transportation Planning and Technology, 33(7), 569-581.

GRANGER, C.W.J., YOON, G. (2002), Hidden Cointegration. Department of Economics Working Paper University of California, No:2002-02.

HACKER, R.S., HATEMI-J, A. (2008), Optimal Lag Length Choice in the Stable and Unstable VAR Models Under Situations of Homoscedasticity and Heteroscedasticity. Journal of Applied Statistics, 35(6), 601-615.

HAKIM, M. M., MERKERT, R. (2016), The Causal Relationship between Air Transport and Economic Growth: Empirical Evidence from South Asia. Journal of Transport Geography, 56, 120-127.

HATEMI-J, A. (2003), A New Method to Choose Optimal Lag Order in Stable and Unstable VAR Models. Applied Economics Letters, 10(3):135137.

HATEMI-j, A. (2012), Asymmetric Causality Tests with an Application. Empirical Economics, 43(1), 447-456.

HENSHER, D. A., TRUONG, T. P., MULLEY, C., ELLISON, R. (2012), Assessing the Wider Economy Impacts of Transport Infrastructure Investment with an Illustrative Application to the North-West Rail Link Project in Sydney, Australia. Journal of Transport Geography, 24(1), 292305.

HU, Y., XIAO, J., DENG, Y., XIAO, Y., WANG, S. (2015), Domestic Air Passenger Traffic and Economic Growth in China: Evidence from Heterogeneous Panel Models. Journal of Air Transport Management, (42), 95-100.

ITANI, N., O’CONNELL, J. F., MASON, K. (2013), The Impact of Emigrants' Homeland Relations on Air Travel Demand in a Security Volatile Market: A Case Study on Lebanon. Journal of Transport Geography, (30), 170-179.

KOPSCH, F. (2012), A Demand Model for Domestic Air Travel in Sweden. Journal of Air Transport Management, (20), 46-48. 
LUTKEPOHL, H. (1985) "Comparison of Criteria for Estimating the Order of a Vector Autoregressive Process” Journal of Time Series Analysis, (6), 35-52.

MARAZZO, M., SCHERRE, R., FERNANDES, E. (2010), Air Transport Demand and Economic Growth in Brazil: A Time Series Analysis. Transportation Research Part E: Logistics and Transportation Review, 46(2), 261-269.

MOHMAND, Y. T., WANG, A., SAEED, A. (2016), The Impact of Transportation Infrastructure on Economic Growth: Empirical Evidence from Pakistan. Transportation Letters, 9(2), 63-69.

OZAN, C., BAŞKAN, Ö., HALDENBILLEN, S., CEYLAN, H. (2014), Yurtiçi Hava Taşımacılığı Talebinin Modellenmesi ve Senaryolar Altında Değerlendirilmesi. Pamukkale Üniversitesi Mühendislik Bilimleri Dergisi, 29(9), 319-323.

PROFILLIDIS, V., BOTZORIS, G. (2015), Air Passenger Transport and Economic Activity. Journal of Air Transport Management, (49), 23-27.

SHGM (2016), Sivil Havacılık Genel Müdürlüğü Faaliyet Raporu. http://web.shgm.gov.tr/tr/kurumsal/1--tarihce, (02.05.2017).

SIVRIKAYA, O., TUNÇ, E. (2013), Demand Forecasting for Domestic Air Transportation in Turkey. The Open Transportation Journal, (7), 20-26.

TAM, R., HANSMAN, R. J. (2002), Impact of Air Transportation on Regional Economic and Social Connectivity in The United States. American Institute of Aeronautics and Astronautics, 1-11.

TANDOĞAN, D., GENÇ, M. C. (2016), Türkiye'de Turizm ve Ticari Açıklık Arasındaki İlişki: Toda ve Yamamoto Nedensellik Yaklaşımı. International Journal of Economic \& Social Research, 12(1). 59-70.

TODA, H. Y., YAMAMOTO, T. (1995), Statistical Inference in Vector Autoregressions with Possibly Integrated Processes. Journal of econometrics, 66(1), 225-250.

VALDES, V. (2015), Determinants of Air Travel Demand in Middle Income Countries. Journal of Air Transport Management, (42), 75-84. 


\section{K.KİRACI}

VAN DE VIJVER, E., DERUDDER, B., WITLOX, F. (2014), Exploring Causality in Trade and Air Passenger Travel Relationships: The Case of Asia-Pacific, 1980-2010. Journal of Transport Geography, (34), 142-150.

YILANCI, V., BOZOKLU, S. (2014), Türk Sermaye Piyasasında Fiyat ve İşlem Hacmi İlişkisi: Zamanla Değişen Asimetrik Nedensellik Analizi. Ege Akademik Bakış, 14(2), 2-11.

WORLDBANK, (2017), http://databank.worldbank.org/data/home.aspx, (02.01.2017). 